\title{
A technology-enhanced framework for supporting peer instruction and just-in-time teaching in flipped English classrooms
}

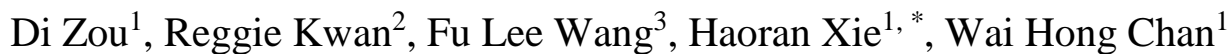 \\ ${ }^{1}$ The Education University of Hong Kong, Hong Kong \\ ${ }^{2}$ The Open University of Hong Kong, Hong Kong \\ ${ }^{3}$ Caritas Institute of Higher Education, Hong Kong
}

\begin{abstract}
As acknowledged by educational communities, flipped classroom has been a novel and useful teaching model for digital classroom. However, it seems difficult and unclear for many teachers to implement flipped classroom in their lectures in practice. To solve this issue, this article explains how to conduct flipped teaching effectively and efficiently in English classes by adopting recent technologies. Specifically, a technology-enhanced framework is proposed to support peer instruction and just-in-time teaching in the flipped classroom model. Furthermore, issues such as how to select suitable and specific technical tools, and which functions/components should be included in the framework are introduced. In addition, this article reports on a work in progress project that flips a course of English for Specific Purposes with peer instruction and just-in-time teaching. The objectives of this project as well as the way to implement the proposed framework in real scenarios are presented. In depth analysis concerning technology-enhanced language learning, e-learning frameworks, and how such a flipped classroom facilitated students' language enhancement and critical thinking skills are also included.
\end{abstract}

\section{Introduction}

As commonly acknowledged by various research communities in education, flipped classroom is an effective teaching model which will give more opportunities for interactions and hands-on practices, cultivating the critical thinking skills by moving the traditional classroom instructions to the time out of classes.

There are several formal definitions for the flipped classroom. The straightforward definition for flipped classroom - "inverting the classroom means that events that have traditionally taken place inside the classroom now take place outside the classroom and vice versa” was given by Lage, Platt, and Treglia [17]. In other words, this definition of flipped classroom indicates re-arrangements of in-class and out-class activities. In many research studies [16], [11], group learning classroom activities such as group practice projects are usually adopted in the classroom.

Furthermore, Bishop \& Verleger [12] proposed an extended definition of flipped classroom which consists of two components: interactive group learning activities inside the classroom, and direct computer-based individual instruction outside the classroom. As shown in Figure 1, the activities inside classroom employ student-centered learning theories and group interactive activities which are difficult to be widely implemented by information technology, while the activities outside classroom are based on student-centered learning theories and traditional instruction which can be easily and automatically implemented by computer technology. Although flipped classroom is an effective teaching model, it is still difficult and unclear for teachers to implement the flipped classroom in their own lectures in practice.

Therefore, in this article, we answer the question "how to implement a flipped classroom in an effective and efficient way for English teaching classrooms by adopting the recent technologies”. For English teaching, we further argue that the peer instruction (PI) and Just-in-time teaching (JiTT) should be integrated and supported in the flipped classroom.

Peer instruction, according to Mazur [7], is an interactive approach to learning and teaching. Its major special feature is the provision of students with rich opportunities to discuss and negotiate, and it is believed that such interactions facilitate students to learn from each other. Typical activities for peer instruction are collaborative classroom exercises like group discussions and negotiations. 


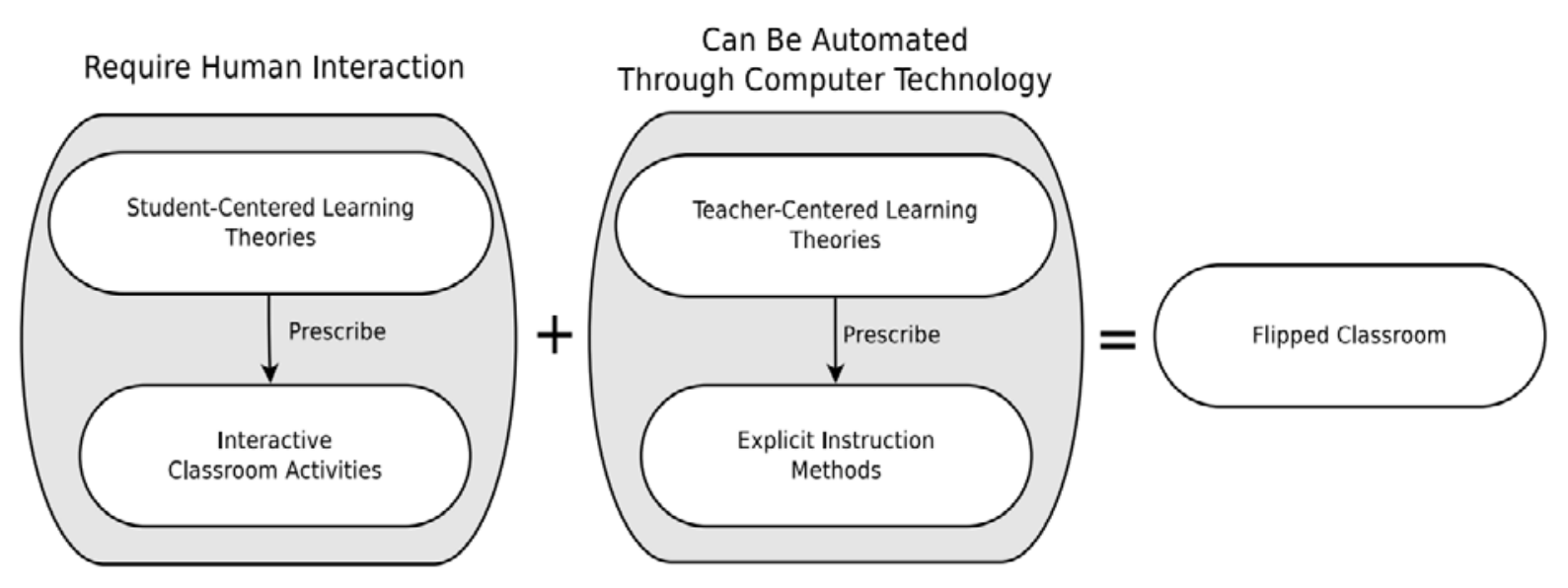

Figure 1. The conceptual definition of flipped classroom [12]

Just-in-time teaching (JiTT) creates a feedback loop between students' online learning at home and interactions in class [9], so it is normally conducted as a complement to PI. JiTT is the before-class part, and PI is the in-class part. Through assigning online learning tasks for students to complete before class and monitoring their progress, JiTT helps students understand the basic content of a class, so the students can better participate in the higher-order thinking activities in class. JiTT also facilitates teachers to know to what extent students have achieved the expected learning outcomes and further tailor the PI questions based on students' performance in the JiTT [5]. Moreover, teachers can fine-tune their planned classroom activities to better meet students' needs according to what they observe from students' answers to the JiTT exercises. Therefore, JiTT and PI work well together as an effective approach to flipping classes and promoting active learning. They have been widely employed in various science and engineering disciplines (e.g., physics, biology, information and computer science, etc.) ever since they were proposed in the late 1990s. Surprisingly, not many language teachers have applied JiTT and PI in their classes. This project therefore aims to initiate the attempts. PI and JiTT seem conducive to language education because they involve many studentcentered and collaborative activities, and hence provide rich opportunities for students to practice language skills [5]. Moreover, as effective language learning involves group work to a large extent, PI is likely to be very effective for language enhancement. Additionally, empowering students to do the JiTT exercises anywhere anytime may release students' anxiety of foreign language learning and increase their confidence. Conducting classroom activities that aim to promote peer teaching and learning can also increase students' motivation and improve their communication skills and problem-solving abilities. Therefore, the proposed research aims to investigate
PI and JiTT in English language education and discuss how to integrate them in flipped English classroom.

The remaining parts of this articles are organized as follows. In the Section 2, the related research studies in the flipped classroom, PI, JiTT and technology enhanced learning are reviewed. In Section 3, the technology-enhanced framework is proposed and elaborated in a top-down approach. A related project is introduced as a case evidence in Section 4. In Section 5, some experimental results about the flipped classroom from both our pilot study and other related research are discussed. Finally, the conclusion, future work and limitation are presented in the Section 6.

\section{Related Work}

As this research is closely related to the flipped classroom, Just-in-time teaching, peer instruction and computer-assisted learning, related work in these areas will be categorized into two subsections, which are corresponding to pedagogical theories and technical systems.

\subsection{Pedagogical Theories}

PI and JiTT have been applied in classes of a wide variety of disciplines and institutions around the globe, and the practitioners generally agree that they lead to better learning than traditional teaching methods (e.g., [6], [1], [20], [13], [18],; etc.). Because questioning constitutes a major part of PI and JiTT, and teaching by questioning is more effective than by telling [7], teachers who apply PI and JiTT in their classes commonly report that their students are more motivated than before, and they achieve better academic performance. JiTT exercises lead students to learn actively through asking various guided questions; and PI activities help students apply what they have learned [5] Such practices are also conducive to the development of students' critical 
thinking on the course materials and hence further lead to other high order thinking skills such as conceptual reasoning, problem solving and critical thinking skills [3], [19]. This is mainly because a PI classroom involves a large number of opportunities for students to discuss their understanding of the course content, compare their thoughts, and negotiate different opinions when necessary. The whole process is very facilitative for language enhancement and development of various language skills, including reading, speaking and listening.
Moreover, according to the learning pyramid as proposed by the National Training Laboratories in the early 1960s, PI tends to promote a high retention of learning as it induces applying what one has learned and teaching others. The three high order skills such as discussing the knowledge, practice doing it, and teaching others are all induced by a PI class. The learning pyramid predicts the approximate percentages of learner retention induced by various

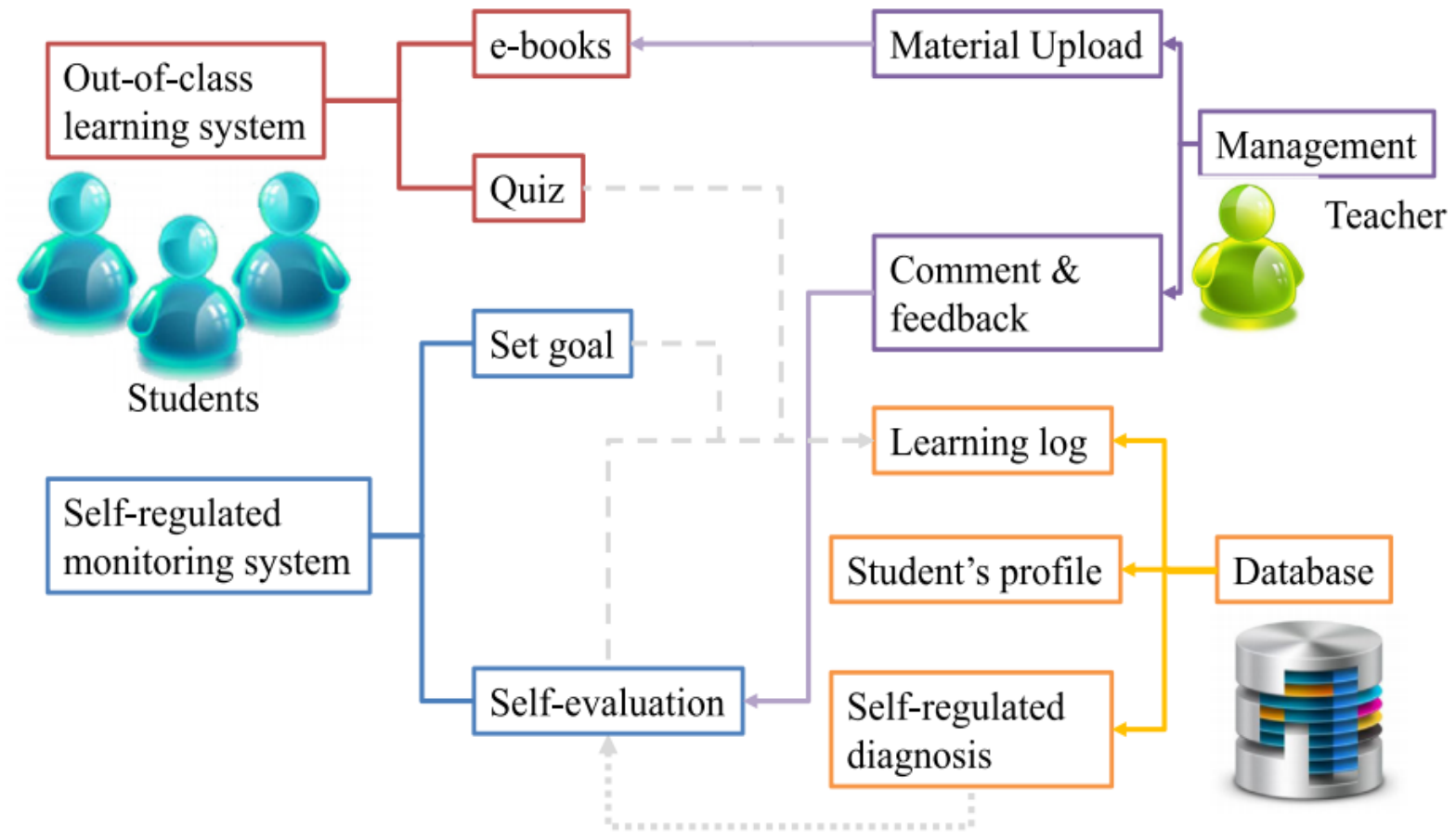

Figure 2. The structure of the self-regulated monitoring system in the flipped classroom (Lai \& Hwang, [4])

learning activities, and it is estimated that $90 \%$ of the target knowledge can be learned if students learn by teaching others, $75 \%$ by practicing the target knowledge, and $50 \%$ if engaging in discussions. This learning pyramid highly emphasizes the importance of knowledge application, active involvement and collaborative interactions, noting that they can significantly increase students' retention rate [15].

These hypotheses are in accordance with Chickering and Gamson's [2] seven principles for good practice in undergraduate education. The seven principles highlight that active participation in class activities, engagement in group discussions that focus on questions requiring comprehension of key knowledge, and integration of frequent studentfaculty contacts are essential for effective learning. Checking against these principles, PI is likely to be very effective as it meets all the suggested principles. Specifically, a PI flipped classroom involves collaboration and interaction, and is not competitive or isolated, so it facilitates development of high order thinking skills and deepens students' understanding of the target knowledge. Route memorization is not encouraged in PI flipped classrooms, and students are guided to discuss the course content, write reflectively about it and relate it to their daily lives [5].

Based on the information concerning students' learning performance while doing the JiTT, teachers of a PI flipped classroom are able to give students prompt and frequent feedback. This is important as students' learning progress can help teachers make decisions concerning whether they may proceed to the next stage of learning. With high expectations on them (i.e., to teach other classmates what they have learned), students are more willing to work harder, think deeper and more critically while doing the JiTT. These preparations before class can further engage students in practices and employment of their talents and effective learning strategies [5] As summarized by Mazur and Watkins [6], the blended use of JiTT and PI personalizes students' learning experience. Teachers also benefit from this approach as the teacher-student relationship can be greatly improved since the online platforms and e-learning systems 
enable them to monitor students' learning progress, offer help when necessary, address students' difficulties individually and deepen their understanding accordingly.

\subsection{Technical Systems}

Many research studies attempt to integrate information technology to enhance the effectiveness of the flipped classroom. For example, the selfregulated monitoring system is adopted in the flipped classroom to address one main limitation which is the difficulty to track and monitor the learning effectiveness of students in their out-class activities [4]. As shown in Figure 2, the self-regulated monitoring system has two main functions which are "set goal" and "self-evaluation". The function "set goal" is to assist students to understand the learning objectives and progresses so that they can set suitable goals according to their own preferences and styles, while the function "self-evaluation" can help them to assess their learning effectiveness by providing a set of exercises.

Flumerfelt \& Green [20] proposed a continuous improvement system called "lean" as a toolkit for teachers to respond to the needs of continuous improvement, instructional improvement and instructional technology improvement. Hwang, Lai, \& Wang [8] has extended the flipped classroom by consolidating the theory with a spectrum of

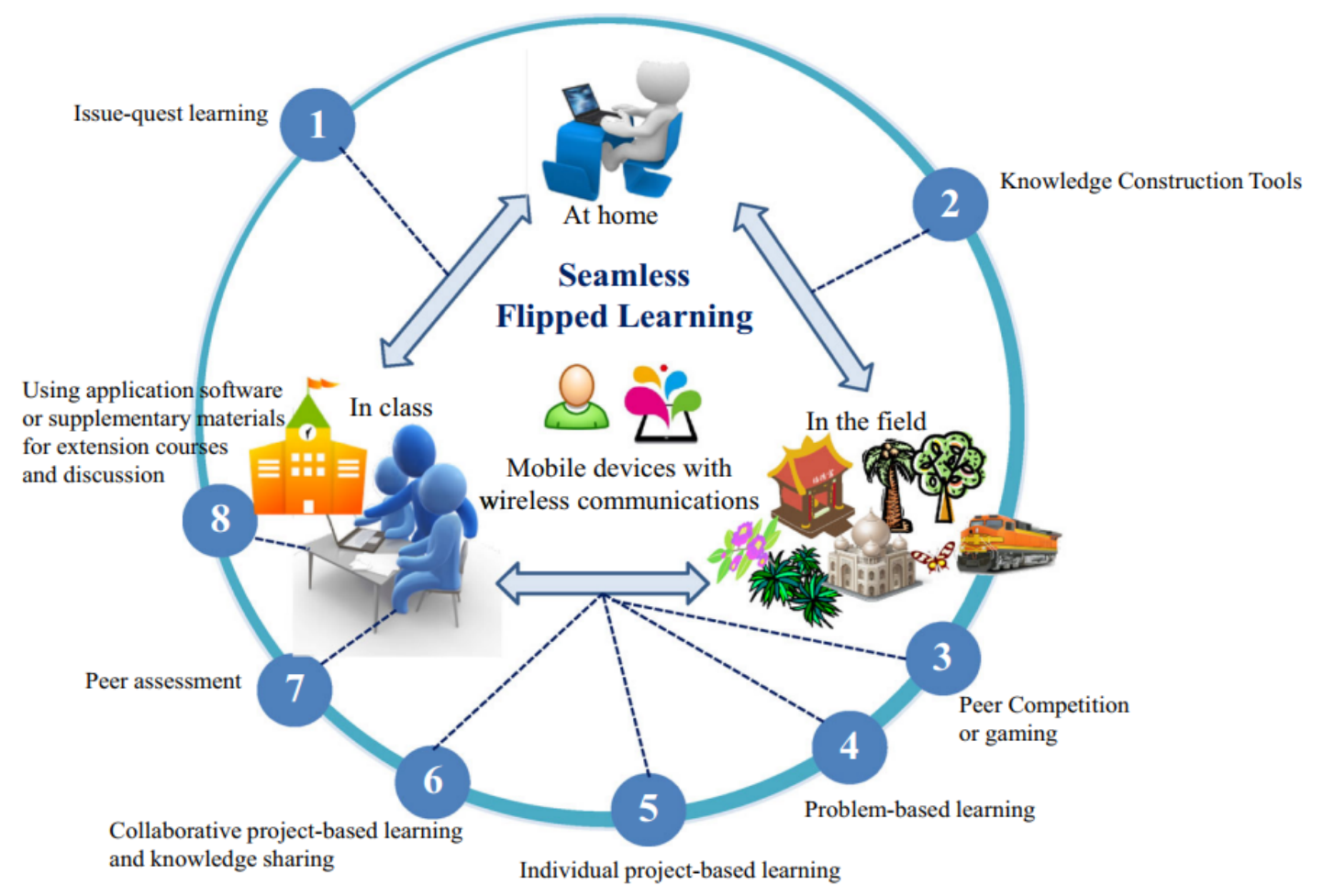

Figure 3. The framework of the seamless flipped classroom enhanced by mobile technologies and various learning techniques (Hwang, et al., 2015)

learning techniques including issue-quest learning, knowledge construction tools, peer competitions or games, problem-solving learning, individual projectbased learning, collaborative project-based learning and knowledge sharing, and peer assessment to establish a seamless learning environment as shown in Figure 3.

Sun, Wu \& Lee [10] incorporate the integration into the flipped classroom model in an open courseware by setting two different groups of learners (i.e., experimental group adopts the flipped classroom and the control group conducts the distance learning in a physics course with 181 freshmen), and identify that there is no significant between-group difference in terms of self-regulation but a distinction in the subcategory of help seeking.

\section{Technology-Enhanced Framework}

Inspired by the concepts and models in the extant research studies in the above section, we will introduce how to establish a technology-enhanced framework by integrating various state-of-the-art techniques to support the flipped classroom model for the English learning. Particularly, facilitating PI and JiTT in the language classroom by using the framework is a major contribution. 
Specifically speaking, the proposed technologyenhanced framework contains three components which are (i) deep learning framework, (ii) flipped classroom framework (containing both out-of-class and in-class activities), and (iii) feedback data as shown in Figure 5.

\subsection{Deep Learning Framework}

The deep learning framework is based on the deep neural network architecture which has been extensively studied in the pattern recognition and machine learning research communities in recent years. Schmidhuber [14] has extensively reviewed various neural networks (NNs) and defined a standard NN structure which contains many simple, connected processors called neurons. Each produces a sequence of real-valued activations. Similar to a real neuron in the human brain, the input neurons are activated by the stimulating signals emitted from sensors in the environment, while other neurons can be activated by a multiple (weighted) connections from previously active neurons [14]. The deep neural networks in the deep learning framework will follow the extant structures to build a powerful artificial intelligent tutor and a learning peer. As illustrated in Figure 4, deep neural network components in the proposed learning framework follow the layered structures. That is, similar to the human brain, the deep neural networks contain many layers of neurons. The input layer receives the input of signals from the training data, the hidden layers receive the signals from previously activated layers, and the output layer receives the signals from the activated neurons in the last hidden layers and then sends the signal out when the neuron is activated.

The training data is a component to process the training files including the historical interaction logs which contains the textual data of questions and answering in the courses, exams, and online learning platforms. The domain knowledge base provides a set of rules and constraints to enhance the power of deduction of the artificial intelligent-based (AI-based) tutor and interactive peer. The knowledge-based rules are extracted from the administrative documentations such as course syllabus, timelines, assessment schema and domain-specific books such as textbook, grammar book, dictionaries, etc. By feeding these documents to the neural networks, the artificial intelligent-based tutor/ interactive peer can reply to administrative questions like "when is the assignment submission due?" "how to submit the group project report?" "can you show me a sentence using the word 'propose' in academic writing?" "can you tell me the meaning of the word 'check' in the context of chess playing?" etc.

The deep learning framework is the core technical component of the overall framework proposed in this article. Furthermore, the learning framework has two characteristics. Firstly, the accuracy of the neural networks can be improved by increasing the training data. In other words, the AI-based tutors and interactive peers will be increasingly knowledgeable and powerful with an increasing use of the overall systems. Secondly, the learning framework can be adapted to the questions/interactions of students without any further human interventions. The AIbased tutor will act as a real tutor for out-class

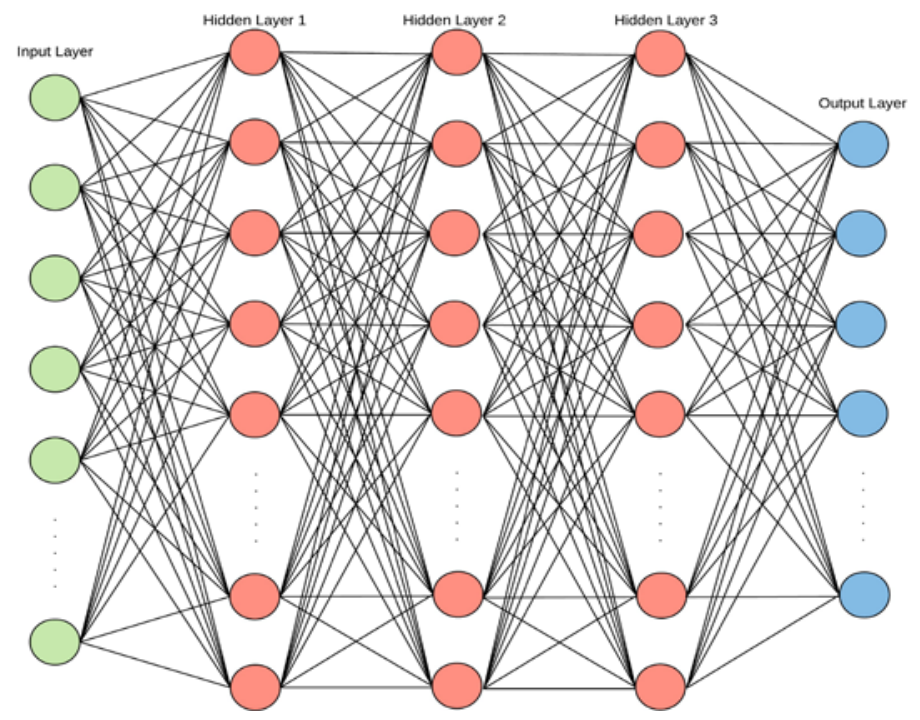

Figure 4. The illustration of the structure of deep neural networks 


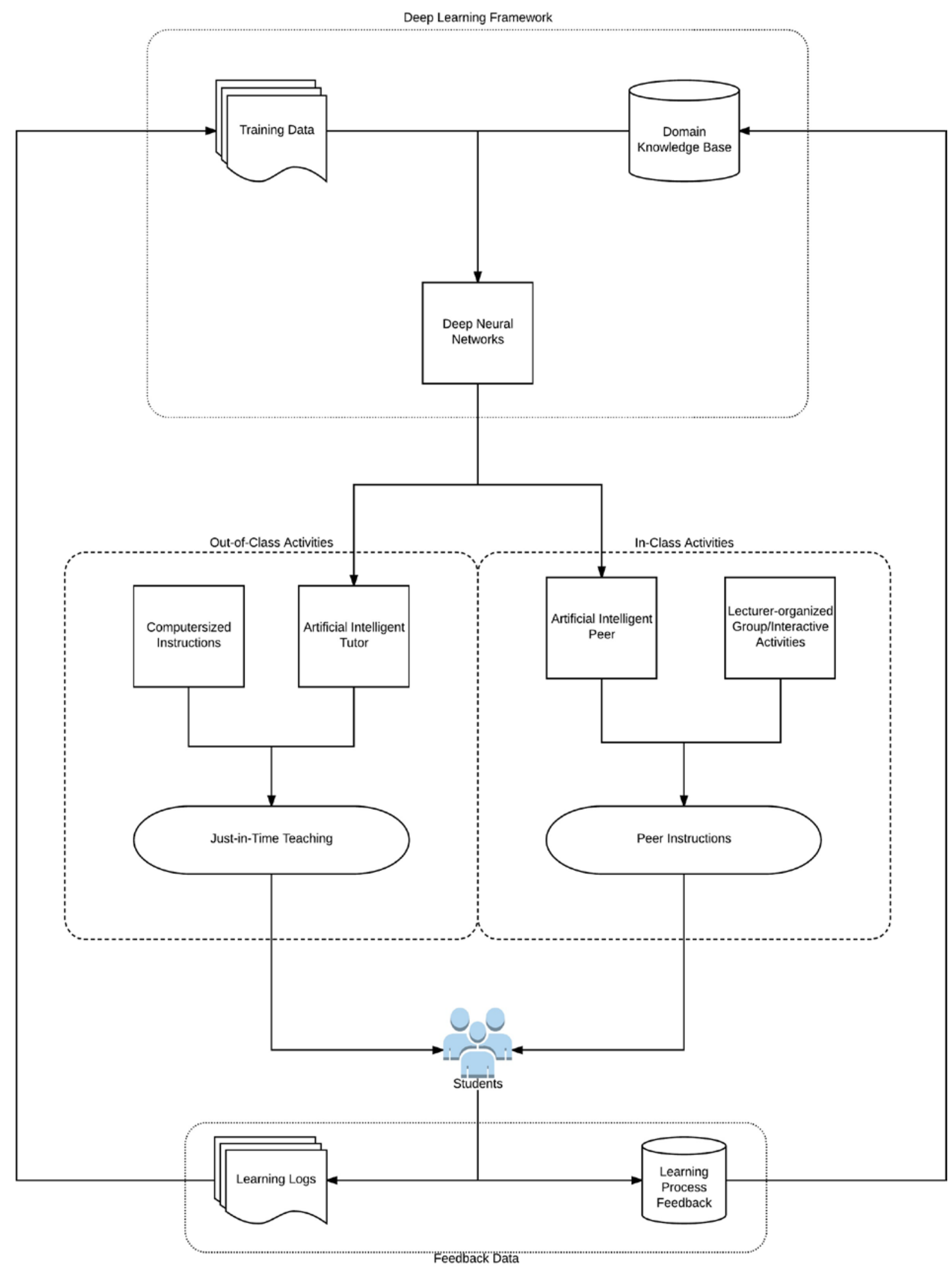

Figure 5. The technology-enhanced framework to support just-in-time teaching and peer instructions for the flipped classroom based on the deep neural networks 
activities, and the AI-based interactive peer can serve as a group member in the interactive in-class activities such as collaborative writing, discussions and so on.

\subsection{The Framework for Flipped Classroom}

The framework for the flipped classroom is consisted of two components. The first component is the of out-of-class activity as shown on the left-hand side of the middle section in Figure 5. The second one is the in-class activity as shown on the right-hand side of the middle section in Figure 5. The details of each component are elaborated as follows.

- Out-of-class Activities (OA). OA plays a key role in learning effectiveness as it is the foundation of success for the flipped teaching mode. Traditional instructions are normally computerized as video lectures, slides, animations and so on. Students can learn the courses through watching these videos and relevant materials. For out-of-class activities, it is impossible and infeasible to have a tutor to respond to all queries from students in a realtime fashion. To facilitate JiTT for OA, it is more practical to adopt an AI-based tutor to timely address all the issues or questions raised by students. AI-based tutors employ the structure of deep neural networks by scanning the historical data about questioning and answering between students and human tutors. In addition, the domain knowledge base enhances the deduction and reduction power of the AI-based tutor to respond to the domainspecific natural languages.

- In-class Activities (IA). IA is the main goal of adopting the flipped mode in a class. Normally, in-class activities are undertaken in the form of group projects or collaborative learning activities. As the conventional instructions are given in OAs, the human tutor can focus on administration and conduct interactive activities. However, it is not possible to have the lecturer involved to stimulate the discussion in each group in the classroom. To address this limitation and increase the amount of peer instructions, a virtual interactive peer instruction based on artificial intelligence is created for each group of students. Different from AI-based tutors, AI-based virtual interactive peers are mainly fed by the training data about the interaction logs in group activities. Similarly, they follow the structure of deep neural networks and extract knowledge rules from the domainspecific knowledge base. By employing these AI-based interactive peers, each group is likely to have richer peer instructions and interactions.

\subsection{Feedback Data Framework}

The final part of the overall framework concerns the feedback data framework. The AI-based tutors and interactive peers will record the learning logs during the interaction, and then use them as the training data for the optimization of neural networks. Another category of data is the suggestion data on learning procedures given by students. After students report to the system, the system administrator will improve the knowledge base by negotiating with the course lecturer.

One main advantage of deep neural networks is that the overfitting problem can be avoided even if the training data is large and the structure is complicated. With such a feedback data framework, the AI-based tutor and the interactive peer will become more reliable and powerful with the increasing amount of accurate data.

\section{Case Project}

In this section, we introduce a case project to be implemented by the proposed technology enhanced framework. The case project is mainly based on an introductory English course in the foundation year of a university.

\subsection{Project Introduction}

The project will flip the course English for Scientific Communications at a local university in Hong Kong or China by taking the language input and information transfer out of class and bringing more knowledge application and language practices into class. Class hours will be structured around collaborative tasks to promote interactions among students. In other words, rather than directly start a class with language input, the JiTT assignments before class instruct students to teach themselves in advance through reading notes, watching videos and answering questions that are intended to promote critical thinking. Therefore, when students come to the class, they will have already obtained a brief idea about the key knowledge points, and what they mainly engage in will basically be PI via group discussions and knowledge applications (e.g., doing synthesizing exercises, analyzing and practicing writing different parts of scientific reports, etc.).

\subsection{Project Objectives}

This project has five main objectives as follows:

1) To implement PI and JiTT to the teaching of a discipline-specific requirement subject: English for Scientific Communication.

2) To flip the classroom by moving the learning of the basic content of the course out of class and integrating 
more group discussions, negotiations, and other forms of language practices into the class.

3) To provide adequate opportunities for students to critically reflect on what they have learned, make use of it, and practice applying it in their output.

4) To develop students' language skills and communication skills and boost their confidence in speaking.

5) To construct a flipped learning model for the course and develop a list of suggestions that aim to help teachers implement PI and JiTT in English classrooms.

\subsection{Project Rationale}

The undergraduate course English for Scientific Communications is selected because it is a disciplinespecific requirement subject with particular knowledge points that are very suitable for developing questions without clear-cut answers to promote discussion and negotiation among students. For example, concerning the content of scientific reports, the question "how to write a good introduction for a scientific report?" may induce numerous different answers that address diverse aspects, all of which may constitute essential moves that matter for writing an introduction. It is such a discussion and negotiation process that promotes language learning and critical thinking most, rather than the attempt to memorize correct answers. Specifically, as listed below, four knowledge points (which are also the four major expected learning outcomes of the course) have been selected to construct the content framework of the proposed peer instruction flipped classroom.

1) The content of scientific reports

2) The structure of scientific reports

3) The language of scientific reports

4) The genre of scientific reports

Another main reason for selecting the course English for Scientific Communications to investigate the application of PI and JiTT in language classroom is that the students of this course, most of whom are advanced intermediate learners with basic writing skills but need more advanced skills for academic and scientific writing, are appropriate participants for the proposed project. Having attended the introductory English courses for university studies (e.g., Practical English for University Studies, English for University Studies, University English for Higher Diploma Students, etc.) and practiced reading and thinking critically in these classes, the majority of these students are capable of doing self-access language learning out-of-class and participating proactively in discussions on relevant topics in-class. In addition, students are willing to and capable of teaching themselves the four knowledge points stated above, according to a preliminary survey.

\subsection{Project Strategy}

1) To ask students to complete reading, videowatching and question-answering tasks online before class, to participate in group discussions and collaborative writing in class, and to apply what they have learnt after class.

2) To structure time in class around collaborative tasks so as to provide rich opportunities for students to learn from each other through correcting possible misunderstandings, consolidating accurate understandings and applying knowledge to practice.

3) To supply students with well-designed prelecture notes, videos and associated guided questions that elicit their critical thinking on the notes, and to organize creative and interactive classroom activities that involve discussions and applications of learning.

4) To integrate numerous and varied types of independent and collaborative learning tasks to engage students, and to allow students to be empowered in the learning process by actively eliciting their feedback and involvement in the designing of teaching materials, planning and the execution of classroom activities

5) To create a learning environment that involves and supports students in the enhancement of their English communication skills and confidence in speaking.

6) To observe and summarize essential factors for effective PI and JiTT, and to construct a model for adopting these techniques in the course English for Scientific Communications.

7) To restructure the materials of English for Scientific Communications by adding a new session named Pre-class Reading at the beginning of every teaching unit (and sub-unit), moving input into these sessions and focusing on output in other in-class sessions that aim to promote knowledge application. Also, questions that intend to elicit students' critical thinking, and associated videos that are expected to be helpful for students' learning of the key knowledge points, will be developed as key parts of the materials.

8) To further develop this model by taking into account the similarities and differences between an introductory English course in the foundation year of a university and other discipline-specific requirement subjects, and to propose an extended model with better compatibility.

\section{Experiments}

There are two empirical evidences to support the proposed framework. The first one is the evidence from a research study done by Lai \& Hwang [4], which illustrates the effectiveness of adopting a selfregulated monitoring system (SRMS) in the flipped classroom as shown in Figure 2. The second evidence 
is the result from the pilot study of the project mentioned in Section 4.

\subsection{Experimental Results from SRMS}

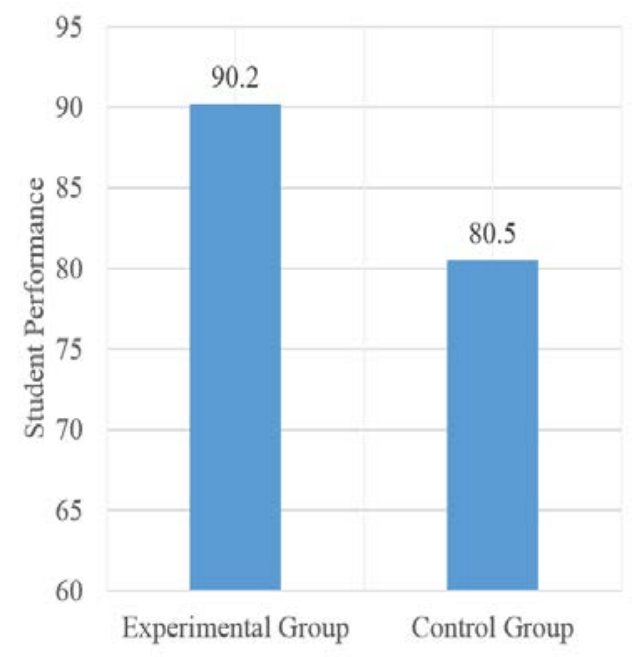

Figure 6. The experimental results from the SRMS [4]

As shown in Figure 6, the experimental results are based on the comparison between a control group and an experimental group.

The control group has 24 students who have taken the conventional flipped classroom, while the experimental group has 20 students who use SRMS. The duration of the overall experiment has lasted for three weeks. In the fourth week, both groups are required to take a post-test within 100 mins to examine the effectiveness of SRMS in the flipped classroom. From Figure 6, we can find that the experimental group has a higher mean than the control group in terms of student performance. The mean performance of the experimental group has about $12.05 \%$ improvement when compared to the control group. The standard deviations are 9.69 and 7.16 in the experimental and control groups respectively.

The experimental results support the effectiveness of the SRMS. In other words, by adding a selfregulated monitoring system, the flipped classroom mode become more effective in student learning than traditional flipped classroom. The technologyenhanced framework proposed in this article has borrowed a similar philosophy as a self-regulated monitoring system. The core idea is to integrate a computerized agent to assist the students to have better understanding about the learning contexts and objectives. Therefore, we can infer that the AI-based tutor and peer will be very effective to further improve the learning effectiveness of the flipped classroom mode.

\subsection{Experimental Results from Pilot Study}

For the project mentioned in Section 4, a pilot study was conducted in a small group with 4 participants. They were invited to participate in the interactive in-class activities like group discussion and group survey in the class. The out-class activities are implemented by various sources such as open courseware platform, internal teaching systems, and external open video communities (e.g., YouTube). They have tried the flipped mode in one lecture and then a survey is conducted.

The survey contains questions fulfilling five criteria. To be specific, these statements are

1) The learning mode can improve your motivation of this course;

2) The learning mode can make you enjoy this course;

3) The learning mode can improve your skills of critical thinking;

4) The learning mode can lead discussions in your group;

5) The learning mode can be effective in taking this course;

Students will answer the survey by giving a score based on a 5-scale Likert rating system where 1 denotes "strongly disagree" and 5 denotes "strongly agree”.

From the experimental result shown in Table 1. We can find that the flipped mode can outperform the nonflipped mode in all five criteria. The table has shown the mean survey results of the four participants.

Therefore, the pilot study can be considered as another evidence of effectiveness of the proposed technology-enhanced framework.

\begin{tabular}{|l|l|l|}
\hline & Flipped Mode & $\begin{array}{c}\text { Non-flipped } \\
\text { Mode }\end{array}$ \\
\hline Motivation & 3.75 & 2.75 \\
\hline Enjoyment & 3.25 & 3.00 \\
\hline Critical Thinking & 3.75 & 3.00 \\
\hline Discussion & 3.5 & 3.00 \\
\hline Effectiveness & 3.75 & 3.25 \\
\hline
\end{tabular}

Table 1. The pilot survey result on the flipped and non-flipped mode in five criteria

\section{Conclusion, Limitation, and Future Work}

In this article, we have proposed a technologyenhanced framework by using the deep neural networks to facilitate the use of AI-based tutors and interactive peers in the flipped classroom. In particular, the proposed framework can support justin-time teaching and peer instructions for English language learning courses. By introducing the case project, we have found that the framework can be 
easily integrated in the domain-specific courses like English for Scientific Communications. In addition, the experimental results from SRMS and pilot study has verified the effectiveness of the framework.

The limitations of this article are two issues. The first is that the number of participants in the pilot study is quite limited that more participants are needed to verify the framework. The second one is that the deep neural networks relies on highperformance computing devices (i.e., Graphical Processing Unit), so it will be expensive for the full deployment of flipped classroom.

There are mainly two directions for our future research. The first direction is to include more participants to examine the effectiveness of the framework. The second direction is to adopt the user profiles as training data for deep neural networks. By exploiting data in the user profiles, the AI-based tutor and interactive peer can have personalized answers for the students.

\section{Acknowledgement}

The research described in this paper was fully supported by the Internal Research Grant (RG 63/2017-2018R) of The Education University of Hong Kong, and a grant from the Research Grants Council of the Hong Kong Special Administrative Region, China (UGC/FDS11/E03/16). This article is an extended work based on a preliminary version which is published in the conference proceedings of CICE 2017 [5].

\section{References}

[1] A. Dumont, "Peer instruction to learn English". In Conference proceedings, ICT for Language Learning, 2013, pp.250.

[2] A. W. Chickering, and Z. F. Gamson, "Seven principles for good practice in undergraduate education", American Association for Higher Education Bulletin, 39(7), 1987, pp. 3-7.

[3] C.H. Crouch, and E. Mazur, "Peer instruction: Ten years of experience and results", American Journal of Physics, 69(9), 2001, pp.970-977.

[4] C. L. Lai, and G. J. Hwang. A self-regulated flipped classroom approach to improving students' learning performance in a mathematics course. Computers \& Education, 100, 2016, pp.126-140.

[5] D. Zou, H. Xie, F. L. Wang, and T.-L. Wong, “Flipping the English for scientific communication classroom with peer instruction and just-in-time teaching" In Canada International Conference on Education, 2017, pp. 433-434.

[6] E. Mazur, and J. Watkins, "Just-in-time teaching and peer instruction", Just in Time Teaching Across the Disciplines, 2010, pp. 39-62.
[7] E. Mazur, and R.C. Hilborn, "Peer instruction: A user's manual”, Physics Today, 50(4), 1997, pp. 65.

[8] G. J. Hwang, C. L. Lai, and S. Y. Wang. Seamless flipped learning: a mobile technology-enhanced flipped classroom with effective learning strategies. Journal of Computers in Education, 2(4), 2015, pp.449-473.

[9] G. Novak, E. Patterson, A. Gavrin, and W. Christian, Just-In-Time Teaching Blending Active Learning with Web Technology, Prentice-Hall, Upper Saddle River, NJ., 1999.

[10] J. C. Y. Sun, Y. T. Wu, and W. I. Lee. The effect of the flipped classroom approach to OpenCourseWare instruction on student's self-regulation. British Journal of Educational Technology, 48(3), 2017, pp. 713-729.

[11] J. E. Gaughan, "The flipped classroom in world history”. The History Teacher, 47(2), 2014, pp. 221-244.

[12] J. L. Bishop, and M. A. Verleger, "The flipped classroom: A survey of the research”. In ASEE National Conference Proceedings, Atlanta, GA, 30(9), 2013, pp. 118.

[13] J.L. Muzyka, "ConfChem conference on flipped classroom: Just-in-time teaching in chemistry courses with Moodle”, Journal of Chemical Education, 92(9), 2015, pp.1580-1581.

[14] J. Schmidhuber. Deep learning in neural networks: An overview. Neural networks, 61, 2015, pp.85-117.

[15] L. W. Anderson, D. R. Krathwohl, and B. S. Bloom, "A taxonomy for learning, teaching, and assessing: A revision of Bloom's taxonomy of educational objectives". Allyn \& Bacon, 2001.

[16] M. Forsey, M. Low, and D. Glance, "Flipping the sociology classroom: Towards a practice of online pedagogy”. Journal of Sociology, 49(4), 2013, pp.471-485.

[17] M. J. Lage, G. J. Platt, and M. Treglia, "Inverting the classroom: A gateway to creating an inclusive learning environment”. The Journal of Economic Education, 31(1), 2000, pp.30-43.

[18] P. Zhang, L. Ding, and E. Mazur, "Peer Instruction in introductory physics: A method to bring about positive changes in students' attitudes and beliefs", Physical Review Physics Education Research, 2016.

[19] S. Butchart, Handfield, and G. Restall, "Using peer instruction to teach philosophy, logic, and critical thinking”, Teaching Philosophy, 32(1), 2009, pp. 1-40.

[20] S. Flumerfelt, and G. Green. Using lean in the flipped classroom for at risk students. Journal of Educational Technology \& Society, 16(1), 2013, 356.

[21] T. Gok, “An investigation of students' performance after peer instruction with stepwise problem-solving strategies", International Journal of Science \& Mathematics Education, 13(3), 2015, pp.561-582. 